\title{
STUDIES ON CROSS-LINKED CHITOSAN HYDROGEL FOR MATRIX TABLETS OF MONTELUKAST SODIUM
}

\author{
SRINIVAS HEBBAR, AKHILESH DUBEY*, RAVI G. S, SHANON BEN MASCARENHAS
}

Department of Pharmaceutics, NGSM Institute of Pharmaceutical Sciences, Nitte University, Deralakatte, Mangaluru 575018, India Email: akhilesh_intas@rediffmail.com

Received: 28 Jan 2017, Revised and Accepted: 14 Jun 2017

\begin{abstract}
Objective: The aim of the present study was to prepare hydrogel matrix tablets for controlled release of an anti-asthma drug (Montelukast sodium) by modifying the applications of chitosan by crosslinking it with the different cross linking agent.

Methods: The hydrogels were prepared by crosslinking chitosan using three different crosslinking agents namely, anhydrous dextrose (DXT), sodium tripolyphosphate (TPP) and glutaraldehyde (GL). Formulations were prepared by direct compression method and pre and post compression parameters were evaluated.

Results: FTIR (Fourier transform infrared spectroscopy) studies of tablet formulation indicated that there is no drug-excipient interaction in the prepared formulations. The matrix tablets were capable of releasing the drug for $11 \mathrm{~h}$ depending upon the formulation variables. The tablets prepared by plain chitosan discharged the drug quickly, while those prepared by using GL crosslinked-hydrogel released the drug more slowly in a controlled manner. In general, the order of drug release from the crosslinked hydrogel matrix tablets on the basis of crosslinking agents, was found to be DXT>TPP>GL. The type of cross-linking agents affected the drug release rate and in the case of the tablets prepared with CHTPP (95 \% to 83 $\%$ ) it was slower than for the tablets prepared with CHDX (96\% to $88 \%$ ) at the end of $11^{\text {th }} \mathrm{h}$. CHGL tablets showed more prolonged drug release profiles (86 \% to $74 \%$ ) as compared to CHDX and CHTPP at the end of $11^{\text {th }} \mathrm{h}$. In vitro release data was fitted into various release kinetic models to study the release mechanism and showed zero order kinetics and " $n$ " value were found to be less than 0.5 indicated the release mechanism followed fickian diffusion due to swelling of gel matrix and high solubility of montelukast sodium.
\end{abstract}

Conclusion: From the experimental results it can be concluded that hydrogels of chitosan were successfully prepared by using DXT, TPP and GL with different concentration.

Keywords: Montelukast sodium, Chemical cross linking, Chitosan, In vitro release

(C) 2017 The Authors. Published by Innovare Academic Sciences Pvt Ltd. This is an open access article under the CC BY license (http://creativecommons.org/licenses/by/4.0/) DOI: http://dx.doi.org/10.22159/ijap.2017v9i4.17445

\section{INTRODUCTION}

Hydrogel is a network of polymer chains that are water-insoluble, sometimes found as a colloidal gel in which water is the dispersion medium. Hydrogels are cross-linked polymer networks that absorb substantial amounts of aqueous solutions. Hydrogels are water-swollen polymer matrices, with a tendency to imbibe water when placed in the aqueous environment. This ability to swell, under biological conditions, makes it an ideal material for use in drug delivery and immobilisation of proteins, peptides, and other biological compounds. Due to their high water content, these gels resemble natural living tissue more than any other type of synthetic biomaterial [1]. These networks have a threedimensional structure, cross-linked together either physically (entanglements, crystallites), or chemically (tie-points, junctions). This insoluble cross-linked structure allows immobilization of active agents, biomolecules effectively, and allows for its release in a well-defined specific manner [2]. Thus the hydrogels biocompatibility and crosslinked structure are responsible for its varied applications [3].

Chitosan, a natural linear bio poly aminosaccharide is obtained by alkaline deacetylation of chitin. The advantage of chitosan over other polysaccharides is that its chemical structure allows specific modifications without too many difficulties at the $\mathrm{C}-2$ position. Specific groups can be introduced to design polymers for selected applications [4]. Cross-linked chitosan are highly useful in the pharmaceutical field for the formulation of various novel drug delivery systems like microspheres, nanospheres, hydrogels and films/membranes. The release of drug from cross-linked chitosan is dependent upon the molecular weight of chitosan, drug content and density of cross-linking. Various therapeutic agents such as anticancer, anti-inflammatory, antibiotics, antithrombic, steroids, proteins, amino acids, antidiabetic and diuretics have been incorporated in cross-linked chitosan microspheres to achieve controlled release as well to enhance bioavailability or for drug targeting to specific areas of the body [5].
The Montelukast sodium is a leukotriene receptor antagonist (LTRA) used for the maintenance treatment of asthma, chronic asthma attacks and to relieve symptoms of seasonal allergies. The main drawback of conventional montelukast sodium formulation is that it undergoes hepatic first pass metabolism. Thus, it shows plasma or biological halflife of 2.5 to $5.5 \mathrm{~h}$, thereby decreasing bioavailability up to $64 \%$.

Therefore, the present work describes such delivery system, which improves the biological half-life as well as the bioavailability of Montelukast sodium [6, 7].

\section{MATERIALS AND METHODS}

\section{Materials}

Montelukast sodium, chitosan, anhydrous dextrose, sodium tripolyphosphate, glutaraldehyde, microcrystalline cellulose, magnesium stearate and talc were purchased from Yarrow Chemicals Pvt Ltd., Mumbai. All the ingredients used were of analytical grade.

\section{Drug and excipient interaction studies}

A physical mixture of drug, polymer and other excipients were prepared and mixed with a suitable quantity of potassium bromide. It was scanned from 4000 to $400 \mathrm{~cm}-1$ in a Bruker FTIR spectrophotometer. Any changes in the chemical composition after combining with the excipients were investigated with IR spectral analysis.

Preparation of cross-linked chitosan hydrogel for matrix tablets of Montelukast sodium crosslinking of chitosan

\section{Crosslinking with anhydrous dextrose (CHDXT)}

A $2 \%(\mathrm{w} / \mathrm{v})$ solution of chitosan in $2 \%(\mathrm{v} / \mathrm{v})$ aqueous solution of acetic acid was prepared by stirring to obtain a clear solution. An appropriate amount of DXT (10\% w/w of dry chitosan) was added under stirring at $120{ }^{\circ} \mathrm{C}$ over a period of $1 \mathrm{~h}$. Then the reaction mixture was allowed to cool to room temperature and cured for two days at $68^{\circ} \mathrm{C}$, followed by 
neutralisation with $10 \%(\mathrm{w} / \mathrm{v}) \mathrm{NaOH}$. The cured mass was cooled to room temperature and acetone was added. Precipitated hydrogel (CHDXT) was separated by decantation and repeatedly washed with distilled water to remove any unreacted material. Further, it was dried at $40^{\circ} \mathrm{C}$ for $24 \mathrm{~h}$, powdered and stored in a well-closed container [8].

\section{Crosslinking with sodium tri polyphosphate (CHTPP)}

A $2 \%$ of chitosan was dissolved in $2 \%(\mathrm{v} / \mathrm{v})$ aqueous acetic acid solution by stirring to get a clear solution. To this solution, $10 \%$ (w/w of dry chitosan) of TPP was added and kept at $4{ }^{\circ} \mathrm{C}$ for $1 \mathrm{~h}$ and the $\mathrm{pH}$ of the solution was maintained at 5.5 Acetone was added to precipitate the hydrogel and the obtained hydrogel (CHTPP) was repeatedly washed with distilled water to remove any unreacted material. Further, it was dried at $40{ }^{\circ} \mathrm{C}$ for $24 \mathrm{~h}$, powdered and stored in a well-closed container $[8,10]$.

\section{Crosslinking with glutaraldehyde (CHGL)}

Chitosan solution $(2 \% \mathrm{w} / \mathrm{v})$ was prepared by stirring in $2 \%(\mathrm{v} / \mathrm{v})$ aqueous acetic acid solution using a homogeniser until the chitosan dissolved completely. To this solution, GL $(10 \% \mathrm{w} / \mathrm{w}$ of the dry weight of chitosan), $0.5 \mathrm{ml}$ of $0.1 \mathrm{~N} \mathrm{HCl}$ were added and mixed for 1 $\mathrm{h}$ at $50^{\circ} \mathrm{C}$. Acetone was added and the precipitated hydrogel (CHGL) was repeatedly washed with distilled water to remove unreacted material. Further, it was dried at $40{ }^{\circ} \mathrm{C}$ for $24 \mathrm{~h}$, powdered and stored in a well-closed container $[8,10]$.

\section{Preparation of Hydrogel matrix tablets}

A total number of 16 formulations were prepared by direct compression method. Sustained release matrix tablets of Montelukast sodium were prepared by using the drug and various concentration of prepared hydrogels CHDX, CHTPP and CHGL and also talc and magnesium stearate were added as glidant and lubricants, while microcrystalline cellulose was used as diluent. All ingredients were passed through a \# 80 sieve, weighed and blended. The lubricated formulations were compressed by direct compression technique. Each tablet weighing $100 \mathrm{mg}$ was formulated are shown in table 1 [9-11].

Table 1: Composition of montelukast sodium matrix tablet

\begin{tabular}{|c|c|c|c|c|c|c|c|c|}
\hline $\begin{array}{l}\text { Formulation } \\
\text { code }\end{array}$ & $\begin{array}{l}\text { chitosan } \\
\text { (mg) }\end{array}$ & $\begin{array}{l}\text { CHDX } \\
\text { (mg) }\end{array}$ & $\begin{array}{l}\text { CHTPP } \\
\text { (mg) }\end{array}$ & $\begin{array}{l}\text { CHGL } \\
\text { (mg) }\end{array}$ & $\begin{array}{l}\text { active } \\
\text { drug (mg) }\end{array}$ & $\begin{array}{l}\text { MCC } \\
(\mathrm{mg})\end{array}$ & $\begin{array}{l}\text { magnesium stearate } \\
\text { (mg) }\end{array}$ & $\begin{array}{l}\text { talc } \\
(\mathrm{mg})\end{array}$ \\
\hline F1 & - & 44 & - & - & 10 & 43 & 2 & 1 \\
\hline F2 & - & 41 & - & - & 10 & 46 & 2 & 1 \\
\hline F3 & - & 44 & - & - & 10 & 43 & 2 & 1 \\
\hline F4 & - & 41 & - & - & 10 & 46 & 2 & 1 \\
\hline F5 & - & 42 & - & - & 10 & 45 & 2 & 1 \\
\hline F6 & - & - & 44 & - & 10 & 43 & 2 & 1 \\
\hline F7 & - & - & 42 & - & 10 & 45 & 2 & 1 \\
\hline F8 & - & - & 44 & - & 10 & 43 & 2 & 1 \\
\hline F9 & - & - & 46 & - & 10 & 41 & 2 & 1 \\
\hline F10 & - & - & 42 & - & 10 & 45 & 2 & 1 \\
\hline F11 & - & - & - & 44 & 10 & 43 & 2 & 1 \\
\hline $\mathrm{F} 12$ & - & - & - & 41 & 10 & 46 & 2 & 1 \\
\hline F13 & - & - & - & 45 & 10 & 42 & 2 & 1 \\
\hline F14 & - & - & - & 42 & 10 & 45 & 2 & 1 \\
\hline F15 & - & - & - & 41 & 10 & 46 & 2 & 1 \\
\hline F16 & 40 & - & - & - & 10 & 47 & 2 & 1 \\
\hline
\end{tabular}

CHDX-Crosslinking with anhydrous dextrose, CHTPP-Crosslinking with Sodium tri polyphosphate, CHGL-Crosslinking with glutaraldehyde, MCCMicrocrystalline Cellulose

\section{Evaluations}

Post compression parameters such as hardness, friability test, weight variation, the thickness of tablet, drug content studies were conducted as per the method is given in IP [12].

\section{Swelling study}

The equilibrium swelling of the hydrogel tablets was studied by mass measurement. Accurately weighed tablets were incubated with $100 \mathrm{ml}$ phosphate buffer solutions of $\mathrm{pH} 1.2$ and 7.4 at $37^{\circ} \mathrm{C}$. The tablets were taken out after $8 \mathrm{~h}$ and blotted carefully, without pressing hard, to remove the excess surface liquid. The swollen tablets were weighed using the electronic balance and the swelling ratio was calculated. [13-15].

\section{In vitro dissolution study}

In vitro drug release study was carried out using a USP-23 rotating dissolution tester. The dissolution was measured at $37.0 \pm 0.5^{\circ} \mathrm{C}$ and $50 \mathrm{rpm}$ speed. The drug release from the tablets was studied in 900 $\mathrm{ml}$ acidic medium $(\mathrm{pH} 1.2)$ for $2 \mathrm{~h}$ and in alkaline medium $(\mathrm{pH} 7.4$ Phosphate buffer) till the end of the study.

At predetermined time intervals, $5 \mathrm{ml}$ aliquots were withdrawn and replaced with the same volume of fresh solution. The amount of drug released was analysed using a UV-Visible spectrophotometer (Shimadzu-1700, Kyoto, Japan), at $\lambda_{\max }$ of $345 \mathrm{~nm}$. [16, 17].

\section{Kinetic release of in vitro release data}

The obtained data were fitted to various mathematical models such as zero order release kinetics, Higuchi model, and KorsmeyerPeppas models to find which model is the best fit for the release profile obtained.

\section{RESULTS AND DISCUSSION}

The characteristic absorption peaks of chitosan and cross-linking agents were obtained at $3292.08 \mathrm{~cm}^{-1}, 2329.12 \mathrm{~cm}^{-1}, 2765.55 \mathrm{~cm}^{-1}$, $2407.85 \mathrm{~cm}^{-1}$. IR Spectrum of the chitosan showed the characteristics peak at $3292.08 \mathrm{~cm}^{-1}$ (NH stretching group), 2329.12 $\mathrm{cm}^{-1}$ (-NH bending group), $2765.55 \mathrm{~cm}^{-1}$ (C-C stretching group) and $2407.85 \mathrm{~cm}^{-1}\left(\mathrm{SO}_{2}\right)$ stretching group as showd in fig. 1 . The characteristic absorption peaks of Montelukast sodium were obtained at $761.744 \mathrm{~cm}^{-1}, 1558.2 \mathrm{~cm}^{-1}, 1409.71 \mathrm{~cm}^{-1}, 2545.98 \mathrm{~cm}^{-1}$, $1140.69 \mathrm{~cm}^{-1}, 1732.16 \mathrm{~cm}^{-1}$. (fig. 2, 3). The spectra of formulations showed the presence of peaks in the region of characteristic peaks of drugs confirmed the absence of interaction between the drugs and excipients used in the formulation [18].

\section{Evaluation of crosslinked hydrogel}

\section{Precompression parameters}

All formulations were subjected to the precompression parameters like angle of repose, bulk density, tapped density, hausner's ratio and carr's index results were under acceptable range. 


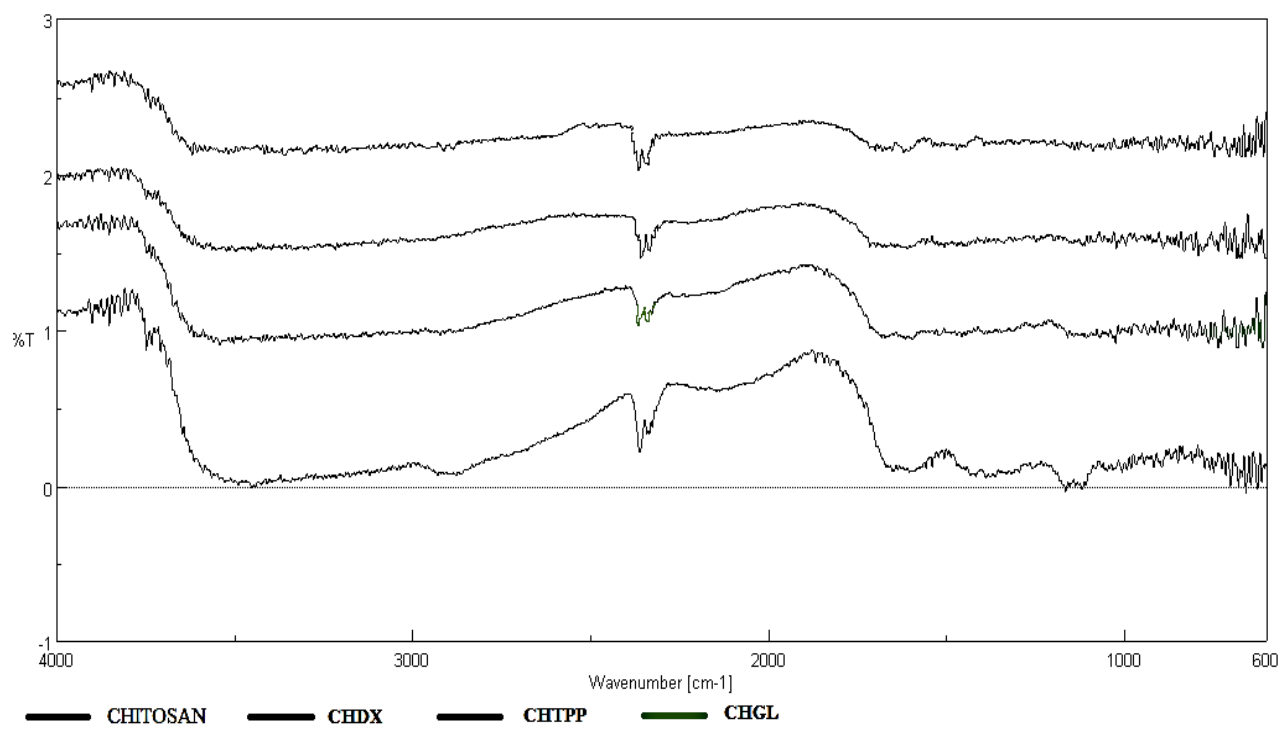

Fig. 1: Characterization of cross-linked chitosan

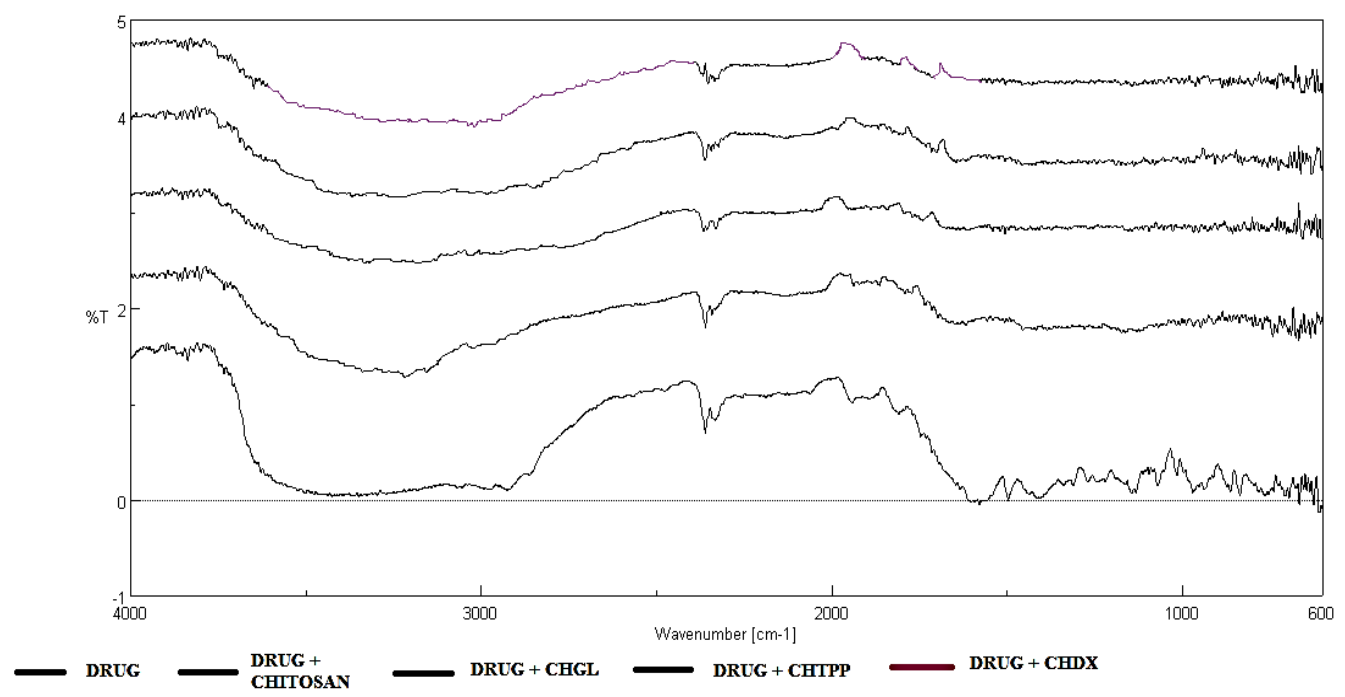

Fig. 2: Drug and polymer interaction

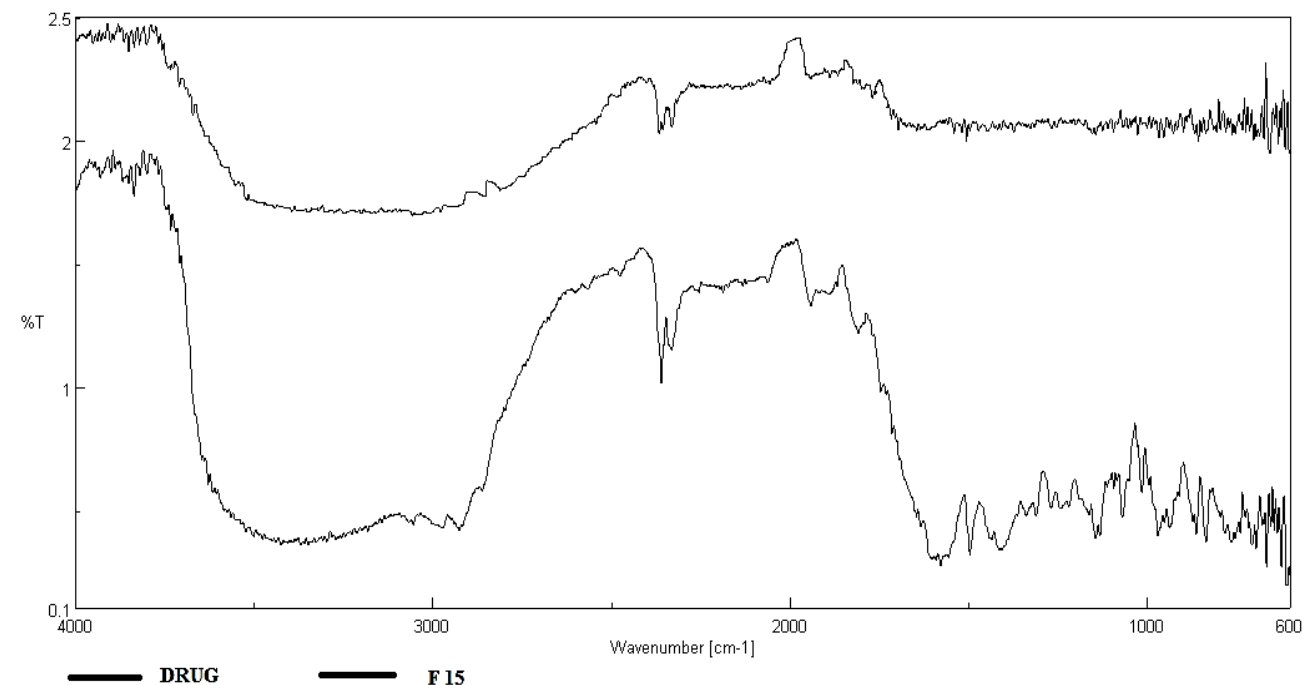

Fig. 3: Drug and formulation study 
Table 2: Pre-compressional parameters

\begin{tabular}{|c|c|c|c|c|c|}
\hline Batch no. & $\begin{array}{l}\text { the angle of repose* } \\
(\theta)\end{array}$ & $\begin{array}{l}\text { bulk density* } \\
\text { (gm/cc) }\end{array}$ & $\begin{array}{l}\text { tapped density* } \\
\text { (gm/cc) }\end{array}$ & hausner's ratio* & $\begin{array}{l}\text { carr's index }{ }^{*} \\
(\%)\end{array}$ \\
\hline F1 & $27^{\circ} 16^{\prime} \pm 0.12$ & $0.254 \pm 0.03$ & $0.295 \pm 0.04$ & $1.23 \pm 0.06$ & $13.76 \pm 0.06$ \\
\hline $\mathrm{F} 2$ & $24^{\circ} 36^{\prime} \pm 0.16$ & $0.267 \pm 0.02$ & $0.288 \pm 0.01$ & $1.11 \pm 0.01$ & $10.63 \pm 0.28$ \\
\hline F3 & $26^{\circ} 16^{\prime} \pm 0.33$ & $0.262 \pm 0.04$ & $0.318 \pm 0.02$ & $1.17 \pm 0.06$ & $15.59 \pm 0.31$ \\
\hline F4 & $28^{\circ} 36^{\prime} \pm 0.16$ & $0.267 \pm 0.02$ & $0.296 \pm 0.04$ & $1.25 \pm 0.02$ & $8.88 \pm 0.11$ \\
\hline F5 & $25^{\circ} 13^{\prime} \pm 0.12$ & $0.262 \pm 0.07$ & $0.295 \pm 0.01$ & $1.18 \pm 0.02$ & $9.48 \pm 0.30$ \\
\hline F6 & $27^{\circ} 36^{\prime} \pm 0.44$ & $0.263 \pm 0.05$ & $0.310 \pm 0.01$ & $1.34 \pm 0.06$ & $12.03 \pm 0.40$ \\
\hline F7 & $29^{\circ} 56^{\prime} \pm 0.32$ & $0.260 \pm 0.02$ & $0.287 \pm 0.01$ & $1.06 \pm 0.01$ & $10.67 \pm 0.26$ \\
\hline F8 & $26^{\circ} 26^{\prime} \pm 0.11$ & $0.263 \pm 0.07$ & $0.296 \pm 0.01$ & $1.17 \pm 0.02$ & $9.58 \pm 0.30$ \\
\hline F9 & $27^{\circ} 18^{\prime} \pm 0.15$ & $0.262 \pm 0.04$ & $0.318 \pm 0.02$ & $1.18 \pm 0.07$ & $15.57 \pm 0.31$ \\
\hline F10 & $27^{\circ} 16^{\prime} \pm 0.13$ & $0.260 \pm 0.02$ & $0.288 \pm 0.01$ & $1.08 \pm 0.06$ & $10.68 \pm 0.26$ \\
\hline F11 & $25^{\circ} 56^{\prime} \pm 0.15$ & $0.264 \pm 0.05$ & $0.320 \pm 0.01$ & $1.33 \pm 0.02$ & $12.13 \pm 0.40$ \\
\hline F12 & $25^{\circ} 17^{\prime} \pm 0.12$ & $0.262 \pm 0.07$ & $0.295 \pm 0.01$ & $1.18 \pm 0.04$ & $9.48 \pm 0.30$ \\
\hline F13 & $24^{\circ} 36^{\prime} \pm 0.24$ & $0.254 \pm 0.03$ & $0.285 \pm 0.04$ & $1.24 \pm 0.03$ & $13.77 \pm 0.06$ \\
\hline F14 & $25^{\circ} 46^{\prime} \pm 0.42$ & $0.260 \pm 0.02$ & $0.287 \pm 0.01$ & $1.09 \pm 0.07$ & $10.68 \pm 0.26$ \\
\hline F15 & $25^{\circ} 36^{\prime} \pm 0.26$ & $0.263 \pm 0.04$ & $0.316 \pm 0.02$ & $1.18 \pm 0.06$ & $15.60 \pm 0.31$ \\
\hline F16 & $26^{\circ} 13^{\prime} \pm 0.12$ & $0.263 \pm 0.05$ & $0.310 \pm 0.01$ & $1.34 \pm 0.02$ & $12.03 \pm 0.40$ \\
\hline
\end{tabular}

* Data are represented as mean $\pm \operatorname{SD}(n=3)$

\section{Post compressional parameter}

All sixteen formulations were prepared by using different concentrations of chitosan, CHDX, CHTPP, and CHGL by direct compression method. The prepared tablets were evaluated for uniformity of weight, hardness, thickness and friability study. All the values of evaluation parameters were well within the range.

\section{Swelling study}

The release of the entrapped drug from the hydrogels depends on the swelling behaviour because the swelling opens up the pores of network and provides a gateway for drug release. The equilibrium swelling study of the hydrogel tablets was carried out in phosphate buffer of $\mathrm{pH}$ 7.4. It was observed that the swelling of hydrogel tablets depends upon the type of crosslinking agents used. The tablets prepared with plain chitosan have shown higher swelling ratio as compared to those prepared with cross-linked-chitosan hydrogel tablets. The swelling of hydrogel tablets was in the order CHDX $>$ CHTPP $>$ CHGL and this observed reverse order, compared to the stiffness order of CHGL $>$ CHTPP $>$ CHDX (fig. 4, 5, 6 and 7). The purpose of measuring swelling index is to determine the ability of hydrophilic polymers used in the formulation to take up water upon hydration. The hydration and swelling behaviour of the polymer is crucial because it is necessary to have an intimate contact with the mucosal membrane. The rate of swelling affects the duration of adhesion with faster swelling resulting in adhesion of shorter duration [19].

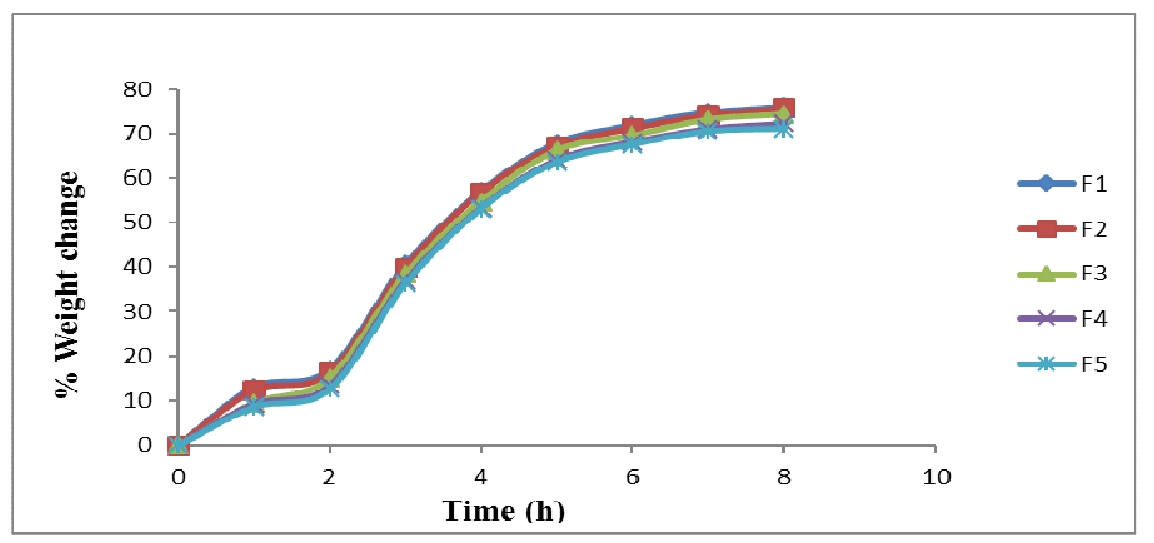

Fig. 4: Swelling data of tablet (cross-linked with anhydrous dextrose), Data are represented as mean \pm SD ( $n=3$ )

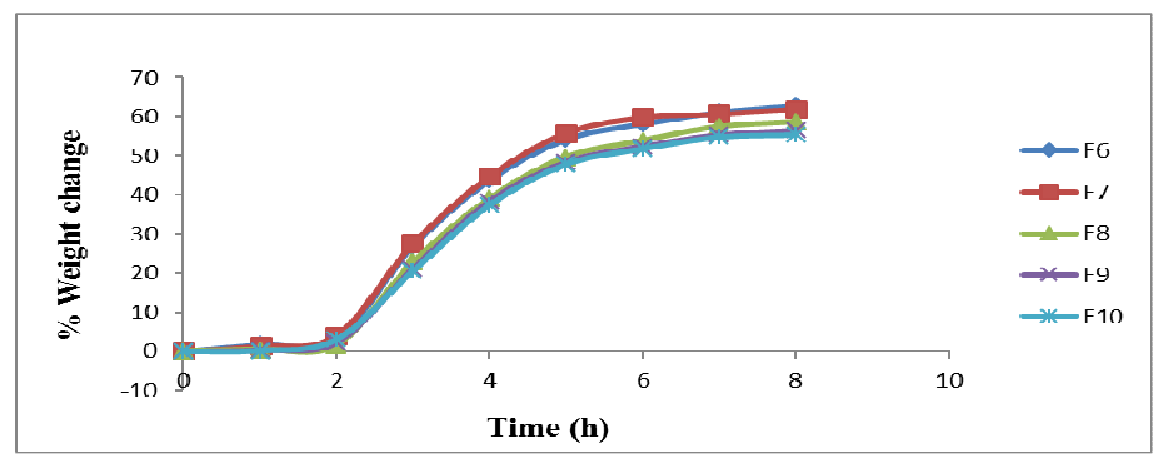

Fig. 5: Swelling data of tablet (cross-linked with sodium tripolyphosphate), Data are represented as mean \pm SD $(n=3)$ 


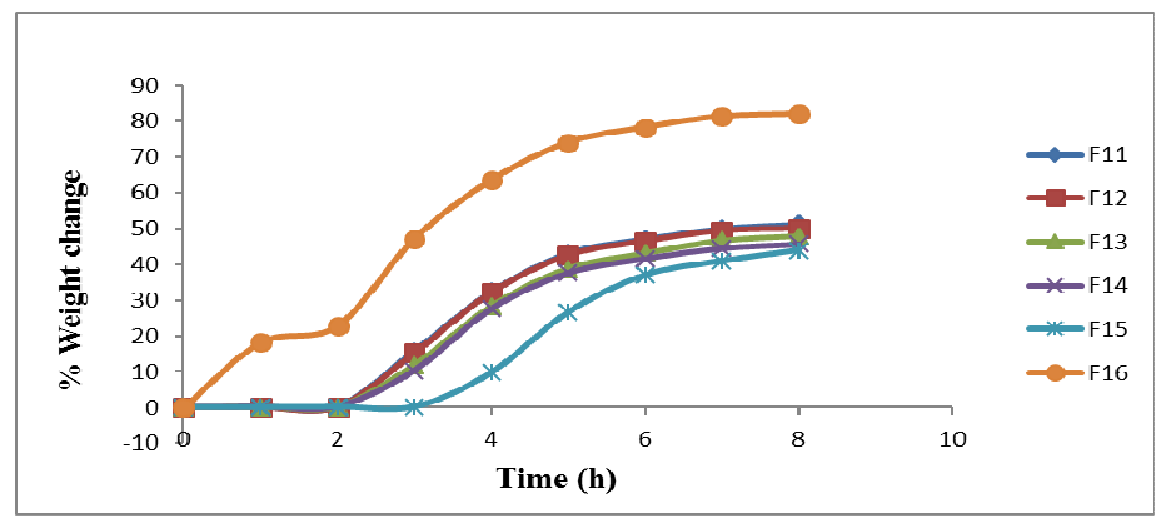

Fig. 6: Swelling data of tablet (cross-linked with glutaraldehyde and chitosan), Data are represented as mean $\pm \operatorname{SD}(n=3)$

Chitosan has a hydrophobic nature, when the chitosan concentration is increased, the hydrophilic character of the hydrogel is decreased. Chitosan does not form ionic links under these conditions and the cross-linking density decreases, the swelling capacity increases. The diffusion coefficients obtained are inversely proportional to the chitosan concentration, and therefore the release rate decreases when the chitosan amount increases. This behaviour confirms that an increase in the hydrogel's chitosan concentration reduces the swelling in neutral medium, and release rate [20]. It is quite evident from the fig. that in the $1^{\text {st }}$ hour there was not much swelling observed but at the end of the $8^{\text {th }}$-hour significant swelling was apparent (fig. 8).

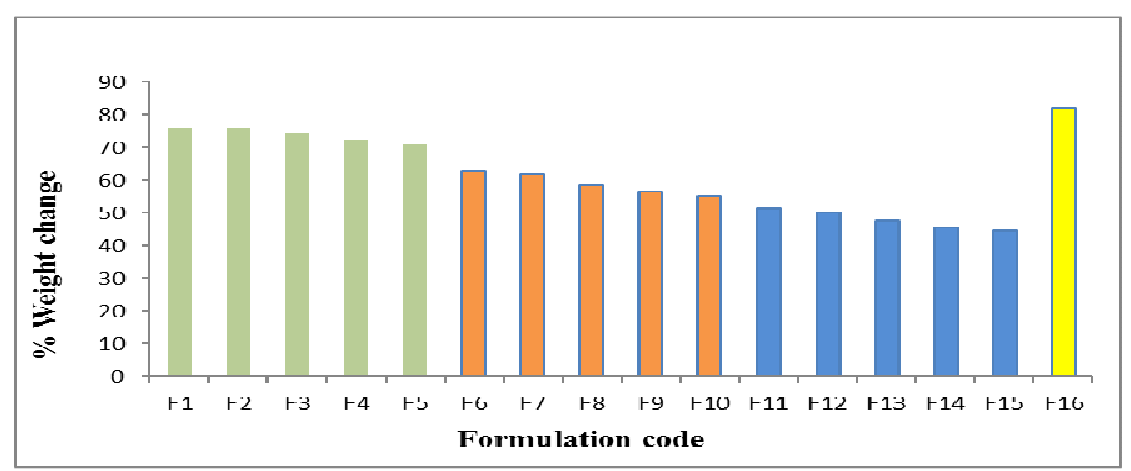

Fig. 7: Effect of chitosan concentration and different cross-linked chitosan hydrogels on swelling behaviour of Montelukast sodium matrix tablet at $8^{\text {th }} \mathbf{h}$

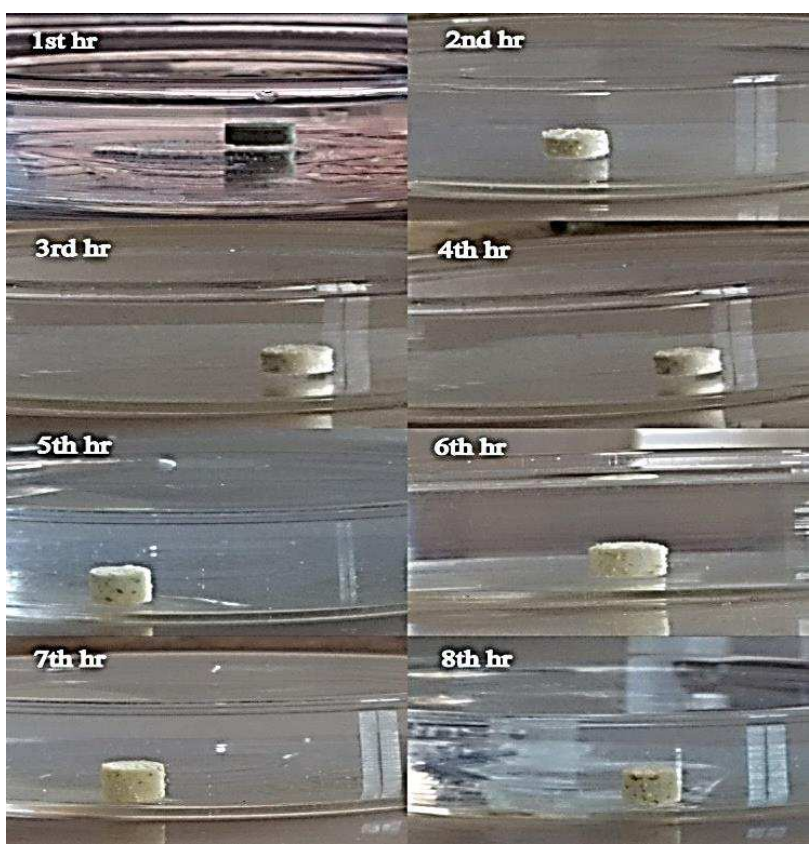

Fig. 8: Effect of chitosan concentration and different cross-linked chitosan hydrogels on swelling behaviour of Montelukast sodium matrix tablet 


\section{In vitro drug release study}

The results of in vitro drug release indicated that the F16 tablets, prepared with plain chitosan, have shown a higher drug release rate in the initial hours, $99.52 \%$ of drug was released at the end of $9^{\text {th }} h$, while the tablets prepared with cross-linked chitosan of different concentration (F1 to F15) have shown progressively slower drug release and some of them have shown promise of releasing the drug more than $11^{\text {th }} \mathrm{h}$ depending upon the formulation variables. The type of cross-linking agents affected the drug release rate and in the case of the tablets prepared with CHTPP (95\% to $83 \%$ ) it was slower than for the tablets prepared with CHDX (96\% to $88 \%$ ) at the end of $11^{\text {th }} \mathrm{h}$. CHGL tablets showed more prolonged drug release profiles ( $86 \%$ to $74 \%$ ) as compared to CHDX and CHTPP at the end of $11^{\text {th }} \mathrm{h}$. This could be due to the formation of stiffer polymer network at higher crosslink densities by decreasing the free volume of the polymer matrix, thereby reducing the movement of drug molecules through the polymer network. This could also reduce the swelling as well as the drug release from the matrix. On the other hand, an increase in cross-linked chitosan hydrogel concentration decreased the release rate of the drug from the polymer matrix. (fig. $9,10,11,12$ ).

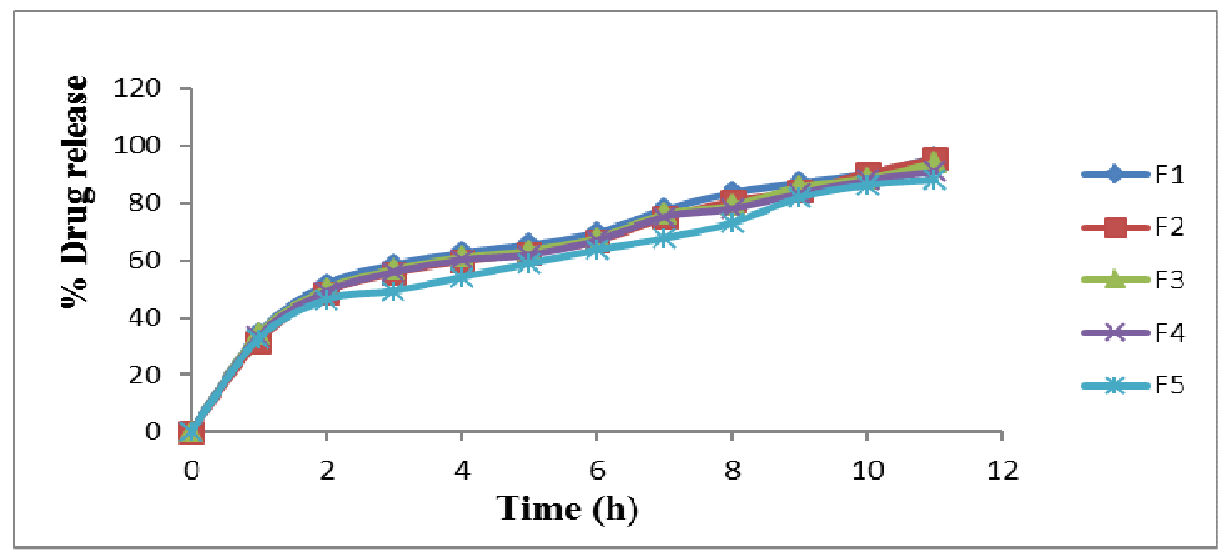

Fig. 9: In vitro drug release study, data are represented as mean \pm SD. (n=3)

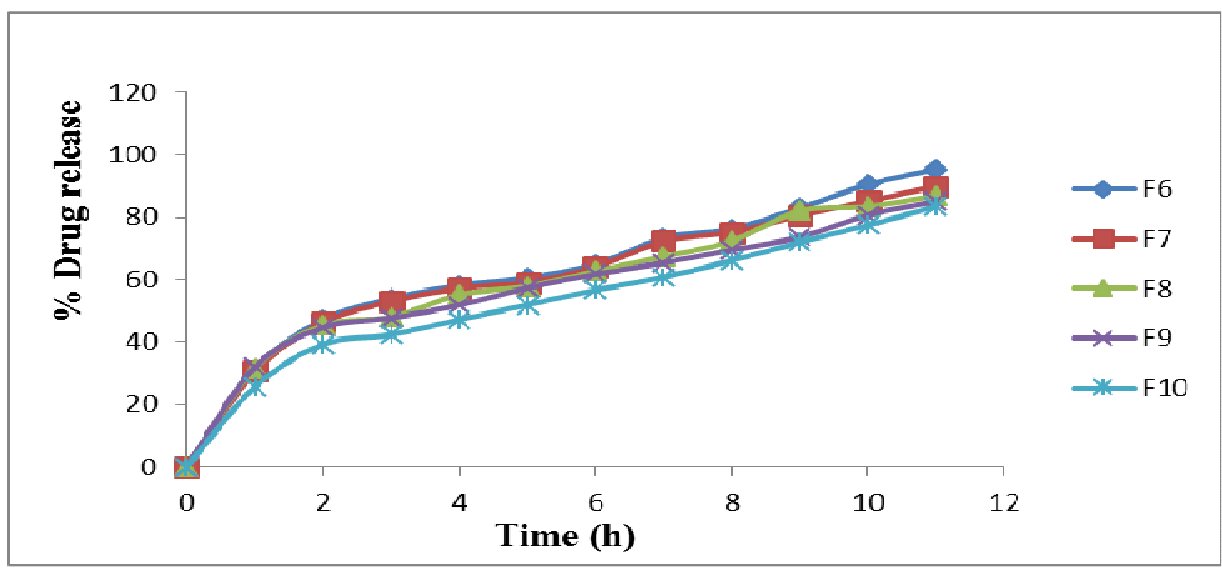

Fig. 10: In vitro release study, data are represented as mean \pm SD. $(n=3)$

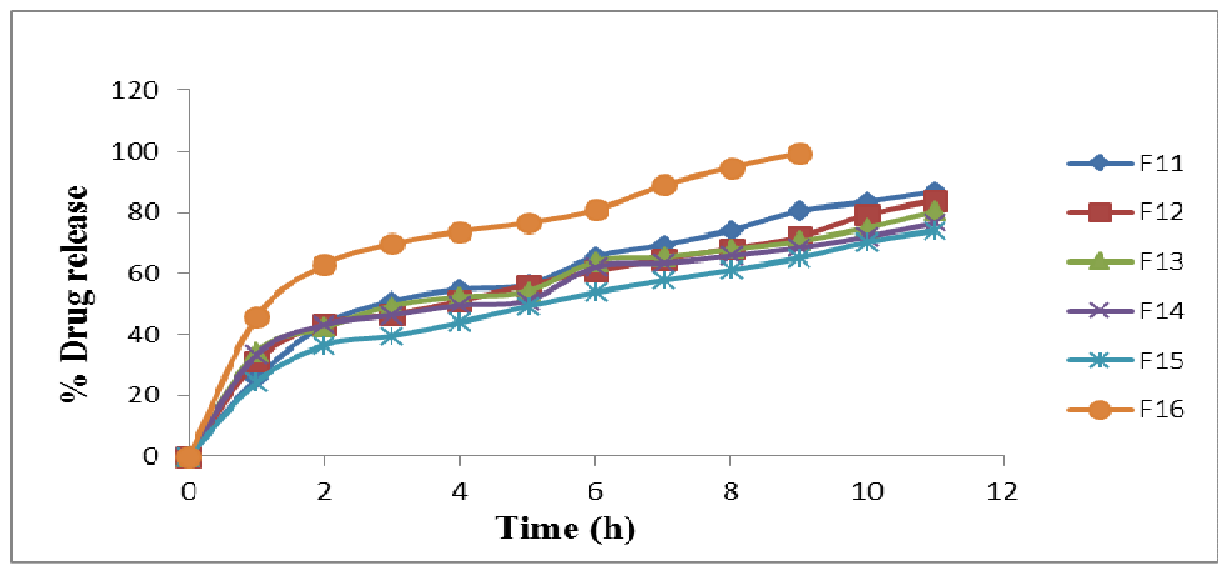

Fig. 11: In vitro drug release study, data are represented as mean $\pm S D$. $(n=3)$ 
Chitosan is a copolymer of $\mathrm{N}$-acetyl-glucosamine and $\mathrm{N}$ glucosamine units distributed randomly or in blocks throughout the biopolymer chain, several interesting properties of chitosan, such as gel and film forming ability, bioadhesion, biodegradability and biocompatibility have been reported. Chitosan has received a great deal of attention in the pharmaceutical field due to its promising properties. Because of the properties of chitosan and polyacrylamide, several works have explored the feasibility of a polyacrylamide/chitosan blend. These studies have reported different aspects of the characterization, biocompatibility, and release properties of polyacrylamide/chitosan hydrogels [20]. Therefore formulation F16 was found to have more release at the end of $11^{\text {th }} \mathrm{h}$ as compared to other formulations because of the presence of chitosan. (fig. 12)

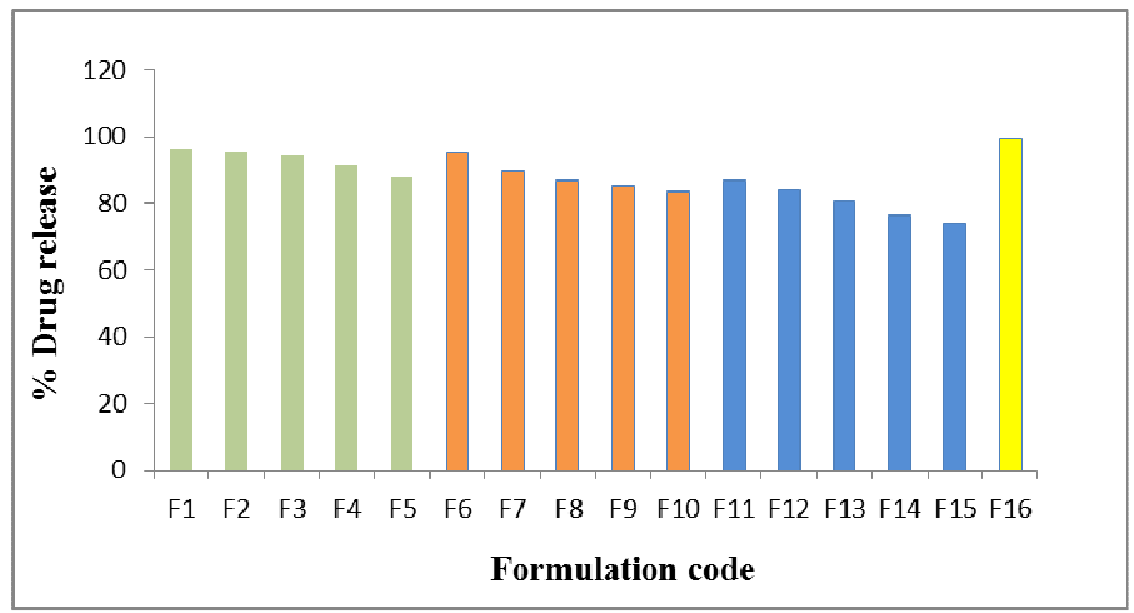

Fig. 12: Effect of chitosan concentration and different cross-linked chitosan hydrogels on in vitro drug release of Montelukast sodium matrix tablet at $11^{\text {th }}$

\section{Release kinetics}

In vitro drug release data was subjected to the goodness of fit test by linear regression analysis according to zero order, first order kinetic equation, Higuchi's and Korsmeyer's-Peppa's models in order to determine the mechanism of drug release. When the regression coefficient values of zero order and first order plots were compared, it was observed that ' $\mathrm{r}$ ' values of zero order plots were in the range of 0.9711 to 0.9941 indicating drug release from most of the formulations was found to follows zero order kinetics. It is notable that the ' $\mathrm{r}^{2}$ ' values of the linear regression for Higuchi's plot were found to be in the range of 0.9703 to 0.9935 indicating that the data fits the Higuchi's model well and the drug release was found to be predominantly controlled by a diffusion process. When the in vitro dissolution data was fitted to Korsmeyer's and Peppa's model, the ' $r{ }^{2}$ ' values were found to be in the range of 0.9705 to 0.9925 in most of the formulations, indicating the data fits the Korsmeyer's and Peppa's model well. The slopes (n) values of Korsmeyer's and Peppa's equation were found to be less than 0.5 indicated the release mechanism followed fickian diffusion due to swelling of gel matrix and high solubility of Montelukast sodium [21].

\section{Stability studies}

The promising formulations were subjected to short term accelerated stability study by storing the formulations at $40{ }^{\circ} \mathrm{C} \pm 2$ ${ }^{\circ} \mathrm{C} / 75 \pm 5 \%$ RH for 3 mo. The formulations are F5, F10 and F15 were selected. After 3 mo the tablets were again analysed for drug content and in vitro drug release profile. The data for stability studies revealed that there were no considerable differences in drug content and dissolution rates.

\section{CONCLUSION}

The present study was an attempt to study and develop the crosslinked chitosan hydrogel for matrix tablet of Montelukast sodium. The main interest behind this study was to observe the release of drug from hydrogel system by cross-linking the polymer i.e. chitosan. It could also improve the bioavailability of drug with prolonged effect. From the experimental results, it can be concluded that hydrogels of chitosan were successfully prepared by using anhydrous dextrose, sodium tripolyphosphate and glutaraldehyde with different concentration resulted with good delayed release properties.

\section{ACKNOWLEDGEMENT}

The authors wish to acknowledge NGSM Institute of Pharmaceutical Sciences, Nitte University, Mangalore, India for providing necessary facilities to carry out this project.

\section{CONFLICT OF INTERESTS}

\section{Declared none}

\section{REFERENCES}

1. Vijay SJ, Himmath S, Santhosh KS. Recent trends on hydrogel in the human body. Int J Res Pharm Biomed Sci 2011;2:442-7.

2. Chauhan S, Harikumar SL, Kanupriya. Hydrogels: a smart drug delivery system. Int J Res Pharm Chem 2012;2:603-14.

3. Zarzyck R, Modrzejewska Z, Nawrotek K. Drug release from hydrogel matrices. Ecol Chem Eng 2010;17:117-36.

4. Ray M, Pal K, Anis A, Banthia AK. Development and characterization of chitosan-based polymeric hydrogel membrane. Des Monomers Polym 2010;13:193-206.

5. Narasimha SM, Ragavendra VK, Ramarao N, Muchandi IS. Cross-linked chitosan hydrogel matrix tablets for controlled release of gabapentin. Farmacia 2012;60:272-86.

6. Abdul HM, Lokeswara VB, Narottam P, Srinivasa RA. Formulation and evaluation of sustained release matrix tablets of montelukast sodium. Int J Pharm 2012;2:574-82.

7. Ragavendra RNG, Abdul MH, Mansoori W, Munde MR, Shrishail MG. Development and evaluation of a tablets-filled-capsule system for chronotherapeutic delivery of montelukast sodium. Int J Pharm Tech 2011;3:1702-21.

8. Thawatchai $\mathrm{P}$, Juree $\mathrm{C}$, Jongjan $\mathrm{M}$. Characterization and in vitro drug release of a chitosan-magnessium stearate monolithic matrix system. Asian J Pharm Sci 2009;4:265-76.

9. Krunal PM, Patel MB, Anil B. Design development and evaluation of modified release tablets of montelukast sodium using ethyl cellulose and tragacanth. Int Res J Pharm 2011;2:175-8.

10. Hima PV, Akshay PR, Janki BB. Formulation, development and evaluation of doxophylline sustained release matrix tablet. Int Res J Pharm 2011;2:204-7.

11. Rahul S, Premchandani TA, Saxena RC. Formulation and evaluation of buccoadhesive tablets of montelukast sodium. Asian J Pharm Clin Res 2011;4:65-8. 
12. Indian Pharmacopoeia published by the Controller of Publication. New Delhi; 2007. p. 242-2.

13. Naresh V, Shivkumar G. Interpenetrating network super porous hydrogels for gastro retentive application preparation, swelling and mechanical properties. Turk J Pharm Sci 2012;9:127-38.

14. Pavitra TK, Harshitha R, Paneer K, Renuka S, Prakash RB, Narendra C. Formulation and evaluation of hydrogel based oral controlled drug delivery system for the antihypertensive drug. J Pharm Sci Technol 2010;2:276-83.

15. Shruthi K, Archana C, Kishore C, Latha K, Thahera D. Preparation and evaluation of montelukast sodium chewable tablets using modified karaya gum. Pharm Sinica 2013;4:125-35

16. Saleem MA, Azaruddin SM, Sadat A, Patil CC. Studies on different chitosan polyelectrolyte complex hydrogels for modified release of diltiazem hydroclhloride. Int J Pharm Sci 2010;2:64-7.

17. Chinedum E, Andrade C, Marcia C, Barretto B, Damian C. Ionically cross-linked chitosan/ tripolyphosphate micro- particles for the controlled delivery of pyrimethamine. Ibosina J Med Biomed Sci 2011;3:77-88.

18. Swapna K, Aparna C, Prathima S. Formulation and evaluation of montelukast sodium and levocetirizine dihydrochloride sublingual tablets. Asian J Pharm Clin Res 2015;8:171-5.

19. Anal AK, Stevens WF. Chitosan-alginate multilayer beads for controlled release of ampicillin. Int J Pharm 2005;290:45-54.

20. Risbud MV, Bhonde RR. Polyacrylamide-chitosan hydrogels: in vitro biocompatibility and sustained antibiotic release studies. Drug Delivery 2000;7:69-75.

21. Ritger PL, Peppa NA. A simple equation of solute release 11 fickian and anomalous from swellable devices. J Controlled Release 1987;5:37-42.

\section{How to cite this article}

- Srinivas Hebbar, Akhilesh Dubey, Ravi GS, Shanon Ben Mascarenhas. Studies on crosslinked chitosan hydrogel for matrix tablets of montelukast sodium. Int J Appl Pharm 2017;9(4):22-29. 